\title{
Raspberry and blackberry pomaces as potential sources of bioactive compounds
}

\author{
Ana Kalušević, Ana Salević, Radovan Đorđević, \\ Mile Veljović, Viktor Nedović
}

\author{
Department of Food Technology and Biochemistry, Faculty of Agriculture, \\ University of Belgrade, Belgrade, Serbia
}

Keywords:

Raspberry

Blackberry

Pomace

Bioactive

Compound

Antioxidant

Activity

Article history:

Received 20.04.2016

Received in revised

form 15.08.2016

Accepted 01.09.2016

Corresponding
author:

Ana Kalušević

E-mail:

ana.kalusevic@

agrif.bg.ac.rs

\section{Abstract}

Introduction. The concern for obtaining some secondary metabolites with health-beneficial effects has initiated studies on valorization of by-products. In this sense, fruit processing by-products have attracted great interest as sources of bioactive compounds.

Materials and methods. Pomaces of raspberry and blackberry were obtained after juice separation. These byproducts were characterized in terms of total phenolic content (TPC) by Folin-Ciocalteu method and total monomeric anthocyanins content (TAC) by $\mathrm{pH}$ differential method. Also, antioxidant activity of pomaces against stable 1,1-diphenyl-2-picrylhydrazyl (DPPH) radicals was evaluated.

Results and discussion. Pomace of blackberry was characterized by significantly higher TPC (10.1 mgGAE/g) and TAC (6 mg C3GE/g) compared to raspberry (8.2 and $3.6 \mathrm{mg} / \mathrm{g}$, respectively). DPPH radical scavenging activity was similar, with slightly higher values in pomace of raspberry (11.7 $\mu$ molTrolox/g) than in blackberry (10.9 $\mu$ molTrolox $/ g$ ). The total soluble solids was $9.3{ }^{\circ} \mathrm{Bx}$ in RP sample, significantly lower than in BP sample with value $14.5^{\circ} \mathrm{Bx}$.

This study indicates that both, raspberry and blackberry pomaces, as wastes of juice production, could be used as a cheap source of bioactive compounds with strong antioxidant activity. Therefore, these pomaces should be considered as a raw material for production of valuable dietary supplements and natural colorants for development of new products with high value added. By-products of fruit processing could be used due to convenience, accessibility and low cost, as suitable way to increase health properties of food. The potential utilization of fruit pomaces could be the enrichment of different products such as bakery products, biscuits, cookies, paste, ice cream, fruit yogurts etc.

Additionally, the potential applications of the ethanol used for bioactive compounds extraction in this study must be considered on the basis of the solvent percent choice, liquid-solid ratio, temperature, and time applied.

Conclusion. Raspberry and blackberry pomaces, discarded during juice production, represent significant sources of bioactive compounds, such as phenolic antioxidants. 


\section{Introduction}

In recent years, food industry has been facing to high expectations that food products should meet consumers' demands for a healthy life style. Therefore, the role of food is not only to satisfy hunger and provide necessary nutrients, but also to prevent nutrition-related diseases and improve consumers' physical and mental well-being [1]. The growing interest in functional food leads to examination for new sources of bioactive compounds [2]. In this regard, the importance of plant secondary metabolites and their potential effects on human health have been intensively studied. Researches indicate that by-products of food processing represent a disposal problem, but also they are promising sources of compounds which could be used because of their convenient technological or high nutritive properties [3].

Berries are rich sources of antioxidants and other bioactive compounds. Many studies claim that the dietary intake of these fruits has positive effects on human health, performance and disease $[4,5]$. Besides high contents of fibers, vitamins and essentials minerals, raspberries and blackberries are known for their high contents of phenolic compounds, such as phenolic acids, tannins, flavonoids and anthocyanins [6, 7]. Raspberries (Rubus idaeus L.) and blackberries (Rubus fruticosus L.) are produced in more than 30 countries worldwide. Despite those berry fruits are often sold and consumed fresh, it represents less than $10 \%$ of produced berries, due to their perishability contributes to nutritional and microbiological deterioration and diminishes quality and health benefits. Thus, large fractions are processed into juices, jams, jellies, syrups, fruit wines, confectionery products, yogurts, and as ingredients of various foods $[5,6,8,9]$.

The high amounts of residues rich in phenolic antioxidants and fibers are produced during industry manufacturing [10]. Nowadays, there is great interest in the recovery of these by-products as raw materials for development of natural food additives and functional food [5]. Additionally, from the economic point of view, fruit processing by-products are the best sources of bioactive compounds and their utilization ensures more effective byproduct management $[7,11]$. The palatable taste and functional properties make berries suitable for obtaining functional food enriched by the valuable compounds [10]. For example, for this purpose, strawberry, sour cherry, raspberry and blackcurrant pomaces were used in order to increase the nutritional values of muffins [11], while raspberry pomace was used as replacement of flour in cookies [2].

The aim of this study was to investigate the potentials of raspberry and blackberry pomaces as sources of bioactive compounds. In this context, the contents of total phenolic compounds and monomeric anthocyanins, as well as 2,2-dyphenyl-1-picrylhydrazyl (DPPH) radical-scavenging activity were determined.

\section{Materials and methods}

Meeker variety raspberry and Čačanska bestrna variety blackberry were cultivated in Aleksandrovac, Serbia. Folin-Ciocalteu reagent and gallic acid were purchased from Merck (Darmstadt, Germany). Sodium carbonate and sodium acetate were supplied by Centrohem (Belgrade, Serbia). DPPH (2,2-dyphenyl-1-picrylhydrazyl) and Trolox (6-hydroxy-2,5,7,8tetramethylchroman-2-carboxylic acid) were provided by Aldrich (Sigma-Aldrich Chemie Steinheim, Germany). Ethanol was procured from Vrenje Spiritana (Belgrade, Serbia). All other chemicals used for the experimental procedures were of analytical grade and used as such without further purification. 
Samples of the berries were stored at $-20{ }^{\circ} \mathrm{C}$ prior to analysis. Pomaces of raspberry (RP) and blackberry (BP) were obtained after juice separation. The extraction of the pomaces was performed with $70 \%$ ethanol solution at room temperature. The weight ratio of pomaces and ethanol was 1:2 in favor of ethanol.

The concentration of soluble solids in samples was measured using Abbe refractometer (Bellinghan \& Stanley Ltd., UK).

Total phenolic content of raspberry and blackberry pomace extracts was determined spectrophotometrically according to the Folin-Ciocalteu method [12]. It is accepted that Folin-Ciocalteu reagent contains complex of phosphotungstate and phosphomolybdate. This method is based on the transfer of electrons from phenolic compounds to molybdenum in alkaline conditions. The result of the reaction is blue complex whose absorbance is measured at $765 \mathrm{~nm}$.

Briefly, $0.5 \mathrm{~mL}$ of diluted extracts were mixed with $2.5 \mathrm{~mL}$ of 10 -fold diluted FolinCiocalteu reagent and allowed to react for 5 minutes. $2 \mathrm{~mL}$ of sodium carbonate solution $(75 \mathrm{~g} / \mathrm{L})$ was added to the mixture and shaken. After $2 \mathrm{~h}$ of reaction at room temperature, the absorbance of the developed blue coloration was measured at $765 \mathrm{~nm}$ against a blank sample_using UV-Vis double beam spectrophotometer (HALO-DB/2S, Dynamica, Switzerland). The calibration curve was prepared using solutions of gallic acid as the standard and the results were expressed as milligrams of gallic acid equivalents per gram of pomace (mg GAE/g).

Total monomeric anthocyanins content of raspberry and blackberry pomace extracts was estimated spectrophotometrically using UV-Vis double beam spectrophotometer (HALO-DB/2S, Dynamica, Switzerland) by $\mathrm{pH}$ differential method [13]. The base of this method is the structural transformation of anthocyanins in change in $\mathrm{pH}$. The monomeric anthocyanins are subject to reversible structural transformation as a function of $\mathrm{pH}$ wherein at $\mathrm{pH}=1$ are in the form of intensively stained flavylium cation and at $\mathrm{pH}=4.5$ taking the form of a colorless hemiketal. The content of anthocyanins is determined by measuring the change in absorbance at two different $\mathrm{pH}$ values $(\mathrm{pH}=1$ and $\mathrm{pH}=4.5)$. The difference in absorbance of a pigment at wavelength of $520 \mathrm{~nm}$ is proportional to the concentration of the pigment. Anthocyanins were quantified as cyanidin-3-glucoside equivalents and resulting values were expressed in terms of milligrams of cyanidin-3-glucoside equivalents per gram of pomace according to the following formula:

Anthocyanin content (cyanidin-3-glucoside equivalents, $\frac{m g}{L}$ ) $=\frac{A \cdot M W \cdot D F \cdot 10^{3}}{\varepsilon \cdot l}$

where:

$$
\begin{aligned}
& \mathrm{A}=\left(\mathrm{A}_{520 \mathrm{~nm}}-\mathrm{A}_{700 \mathrm{~nm}}\right)_{\mathrm{pH} 1.0}-\left(\mathrm{A}_{520 \mathrm{~nm}}-\mathrm{A}_{700 \mathrm{~nm}}\right)_{\mathrm{pH} 4.5} ; \\
& \mathrm{MW}=\text { molecular weight of cyanidin-3-glucoside; } \\
& \mathrm{DF}=\text { dilution factor; } \\
& \mathrm{l}=\text { path lenght }(1 \mathrm{~cm}) \\
& \varepsilon=\text { molar extinction coefficient }(26900 \mathrm{~L} / \mathrm{mol} \times \mathrm{cm}) \\
& 10^{3}=\text { conversion factor. }
\end{aligned}
$$

DPPH radical-scavenging activity of pomace extracts was investigated spectrophotometrically according to the slightly modified procedure described by Kaneda et al. [14] using UV-Vis double beam spectrophotometer (HALO-DB/2S, Dynamica, Switzerland). 2,2-dyphenyl-1-picrylhydrazyl (DPPH) is purple stable free radical with a 
delocalized unpaired electron and with maximum absorbance at $515 \mathrm{~nm}$. Dark purple radical becomes pale yellow hydrazine as the result of reaction between DPPH and antioxidants.

Briefly, diluted extract $(0.2 \mathrm{~mL})$ was added to the DPPH working solution $(2.8 \mathrm{~mL}$, mixture of $1.86 \times 10^{-4} \mathrm{~mol} / \mathrm{L}$ DPPH in ethanol and $0.1 \mathrm{M}$ acetate buffer $(\mathrm{pH}=4.3)$ in ratio 2:1 (v/v)). The mixture was shaken and left at room temperature for $6 \mathrm{~min}$. The absorbance was measured at $515 \mathrm{~nm}$. The Trolox calibration curve was plotted as a function of the inhibition percentage of DPPH radical. The results were expressed as micromoles of Trolox equivalents per gram of pomase (umol TE/g).

All results were obtained in three independent measurements and expressed as mean \pm standard deviation. The experimental data were subjected to One-way analysis of variance (ANOVA) and Tukey's test was used to detect difference $(\mathrm{p} \leq 0.05)$ between the mean values. Statistical analyses were performed with the statistical program STATISTICA 12 (Data Analysis Software System, Stat-Soft, Inc., USA).

\section{Results and discussion}

The extracts of raspberry and blackberry pomace were comparatively evaluated in terms of their antioxidant phytochemicals through assessment of total phenolic and anthocyanin contents, as well as DPPH radical scavenging activity (Figure 1).

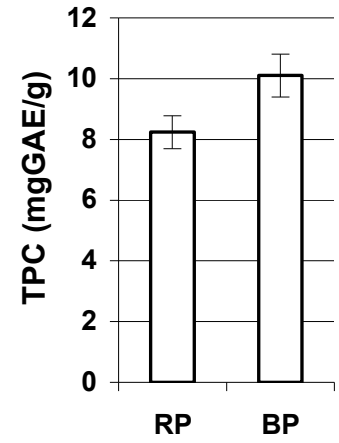

$a$

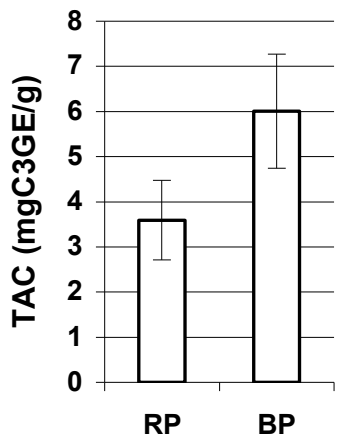

b

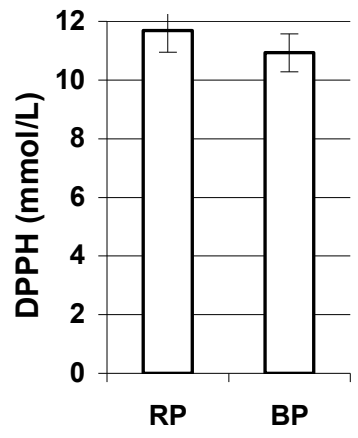

$c$

Fig 1. Total phenolic content (a), total anthocyanin content (b) and antioxidant activity (c) of raspberry (RP) and blackberry pomace (BP)

*The results are expressed as the mean \pm standard deviation $(n=3)$

The results of total phenolic content determined by Folin-Ciocalteu method proved that raspberry and blackberry pomaces contain a high amount of these compounds. As can be seen on Figure 1a pomace of blackberry was characterized by higher TPC (10.1 mg GAE/g) than raspberry ( $8.2 \mathrm{mg} \mathrm{GAE} / \mathrm{g})$. The observed difference was statistically significant at the level of $5 \%$. The combination of pure water with ethanol, as an organic solvent, creates a moderately polar medium favoring the extraction of polyphenols from berries which have moderately polar nature $[7,15,16]$. The obtained results are in accordance with results published by other authors that have also investigated extracts of berry by-products as sources of antioxidant polyphenols $[5,7,16]$. The major concern with polyphenol 
extraction is the effect of increased temperature due to thermal reaction leads to degradation of the polyphenols and formation of Maillard reaction products [16]. All above-mentioned data indicate that the extraction procedure applied in this study represents a good method for the production of phenolic extracts from fruit processing by-products.

The level of total anthocyanins content varied depending on the types of fruit used for juice production. Namely, significantly higher difference has been detected for TAC, where the $\mathrm{BP}$ sample (6 mg C3GE/g) is remarkably dominant compared to RP (3.6 mg C3GE/g) (Figure 1b). It could be explained to some extent with berry structure and composition, such as higher content of total solids and thus potential bindings with anthocyanins and/or similar molecules with sugar or fibers. Specifically in this study, the total soluble solids was $9.3{ }^{\circ} \mathrm{Bx}$ in RP sample, significantly lower than in BP sample with value $14.5^{\circ} \mathrm{Bx}$. It could be concluded that these extracts have a potential as replacements for synthetic food colorants thanks to content of anthocyanins.

Contrary to the results of TPC and TAC, DPPH radical scavenging activity of RP (11.7 $\mu$ molTrolox/g) and BP $(10.9 \mu \mathrm{molTrolox} / \mathrm{g})$ have been statistically insignificantly different, with slightly higher values in RP sample (Figure 1c). It could be explained by the extraction of ellagic acid which expresses strong antioxidant activity and presents the most abundant phenolic compound of raspberry. Additionally, extraction of other compounds, such as vitamin $C$ could contribute to higher antioxidant activity [17]. Additionally, the antioxidant activity of phenolic compounds depends on their structural features and represents ability to scavenge free radicals, donate hydrogen atoms or electron, or chelate metal cations [6]. In that regard, it is necessary to determine the chemical profile of the obtained extracts. Since high portion of these pomaces represents seeds it should be kept in mind that seed oils are rich in not only phenols, but essential omega fatty acids tocopherols, sterols, and carotenoids that have antioxidant properties [18].

As can be seen from the Table 1, coefficient of determination has been higher in case of BP and statistically significant among TPC and DPPH for same sample.

\section{Coefficient of determination between methods used in the study}

Table 1

\begin{tabular}{|c|c|c|c|c|c|c|}
\hline \multirow{2}{*}{$\mathbf{R}^{2}$} & \multicolumn{2}{|c|}{ TPC } & \multicolumn{2}{|c|}{ TAC } & \multicolumn{2}{|c|}{ DPPH } \\
\hline & $\mathrm{RP}$ & BP & $\mathrm{RP}$ & BP & $\mathrm{RP}$ & BP \\
\hline TPC & \multicolumn{2}{|c|}{---} & 0,73 & 1,00 & 0,89 & 1,00 \\
\hline TAC & 0,73 & 1,00 & \multicolumn{2}{|c|}{---} & 0,60 & 1,00 \\
\hline DPPH & 0,89 & 1,00 & 0,60 & 1,00 & & \\
\hline
\end{tabular}

*Bolded numbers are statistically significant

Generally, very important factors represent (pre)treatments applied during processing of berries (e.g. juices production). Application of different temperatures, filtration, enzymes and other biocatalysts have strong influence on the content of bioactive compounds that remains in pomace, beside cultivars as raw material $[8,19,20,21]$. Also, these compounds are enclosed in complex insoluble structures, such as vacuoles of plant cells, thus their extraction is complicated and the potential of new technologies should be studied [22]. 


\title{
Conclusions
}

This study points out that raspberry and blackberry pomaces, discarded during juice production, represent significant sources of bioactive compounds, such as phenolic antioxidants. Resulting residues could be used as cheap sources of potential dietary additives, even natural colorants for development of new products with high value added.

The potential applications of the ethanol for bioactive compounds extraction must be studied on the basis of the solvent percent choice, liquid-solid ratio, temperature, and time applied. Since an economical issue is crucial one for the industrial implementation, the combination of effective extraction and low-cost raw materials is desirable. It represent and environmental and economical solution at the same time, contrary to conventional extraction methods where large amounts of organic solvents and long extraction times are required.

The use of the novel processing technologies will reduce food processing wastes and facilitate the production of natural valuable products which will guarantee food sustainability and also, meet consumer demands for product with healthy constituents.

\begin{abstract}
Acknowledgments
This work is supported by the Ministry of Education and Science, Republic of Serbia, National Integral and Interdisciplinary project: Novel encapsulation and enzyme technologies for designing of new biocatalysts and biologically active compounds targeting enhancement of food quality, safety and competitiveness, III 46010, 2011-2015 and FP7 Project Advancing Research in Agricultural and Food Sciences at Faculty of Agriculture, University of Belgrade (AREA), FP7-REGPOT-0212-2013-I, Ref. no. 316004.
\end{abstract}

\section{References}

1. Menrad K. (2003), Market and marketing of functional food in Europe, Journal of Food Engineering, 56(2), pp. 181-188.

2. Górecka D., Pachołek B., Dziedzic K., Górecka M. (2010), Raspberry pomace as a potential fiber source for cookies enrichment, Acta Scientarium Polonorum Technologia Alimentaria, 9(2), pp. 451-461.

3. Schieber, A., Stintzing F.C., Carle R. (2001), By-products of plant food processing as a source of functional compounds - recent developments, Trends in Food Science \& Technology, 12(11), pp. 401-413.

4. de Souza V.R., Pereira P.A.P., da Silva T.L.T., de Oliveira Lima L.C., Pio R., Queiroz F. (2014), Determination of the bioactive compounds, antioxidant activity and chemical composition of Brazilian blackberrv, red raspberry, strawberry, blueberry and sweet cherry fruits, Food Chemistry, 156, pp. 362-368.

5. Kryževičiūtė N., Kraujalis P., Venskutonis P.R. (2016), Optimization of high pressure extraction processes for the separation of raspberry pomace into lipophilic and hydrophilic fractions, The Journal of Supercritical Fluids, 108, pp. 61-68.

6. Četojević-Simin D.D., Velićanski A.S., Cvetković D.D., Markov S.L., Ćetković G.S., Tumbas Šaponiac V.T., Vulić J.J., Čanadanović-Brunet J.M., Diilas S.M. (2015), Bioactivity of Meeker and Willamette raspberry (Rubus idaeus L.) pomace extracts, Food Chemistry, 166, pp. 407-413. 
7. Machado A.P.D.F., Pasquel-Reátegui J.L. Barbero G.F., Martínez J. (2015), Pressurized liquid extraction of bioactive compounds from blackberry (Rubus fruticosus L.) residues: A comparison with conventional methods, Food Research International, 77, pp. 675-683.

8. Vladisavliević G.T., Vukosavliević P., Veliović M.S. (2013), Clarification of red raspberry juice using microfiltration with gas backwashing: A viable strategy to maximize permeate flux and minimize a loss of anthocyanins, Food and Bioproducts Processing, 91(4), pp. 473-480.

9. Diordiević R., Gibson B., Sandell M., de Billerbeck G.M., Bugarski B., LeskošekČukalović I., Vunduk J., Nikićević N., Nedović V. (2015), Raspberry wine fermentation with suspended and immobilized yeast cells of two strains of Saccharomyces cerevisiae, Yeast, 32(1), pp. 271-279.

10. Mirabella N., Castellani V., Sala S. (2014), Current options for the valorization of food manufacturing waste: a review, Journal of Cleaner Production, 65, pp. 28-41.

11. Górnaś P., Juhneviča-Radenkova K., Radenkovs V., Mišina I., Pugajeva I., Soliven A., Seglina D. (2016), The impact of different baking conditions on the stability of the extractable polyphenols in muffins enriched by strawberry, sour cherry, raspberry or black currant pomace, LWT-Food Science and Technology, 65, pp. 946-953.

12. Singelton V.L., Rossi J.A. (1965), Colorimetry of total phenolics with phosphomolybdicphosphotungstic acid reagents, American Journal of Enology and Viticulture, 16(3), pp. 144-158.

13. Lee J., Durst R.W., Wrolstad R.E. (2005), Determination of total monomeric anthocyanin pigment content of fruit iuices. beverages. natural colorants. and wines by the $\mathrm{pH}$ differential method: collaborative study, Journal of AOAC International, 88(5), pp. 12691278.

14. Kaneda H., Kobayashi N., Furusho S., Sahara H., Koshino S. (1995), Reducing activity and flavor stability of beer, Technical Quarterly-Mater Brewers Association of the Americas, 32(2), pp. 90-94.

15. Vizzotto M., Pereira M.C. (2011), Blackberry (Rubus sp.): extraction process optimization and determination of phenolic compounds antioxidants, Revista Brasileira de Fruticultura, 33(4), pp. 1209-1214.

16. Struck S, Plaza M, Turner C, Rohm H. (2016), Berry pomace-a review of processing and chemical analysis of its polyphenols, International Journal of Food Science \& Technology, 51(6), pp. 1305-1318.

17. Bobinaitè R., Viškelis P., Venskutonis P.R. (2012), Variation of total phenolics, anthocyanins, ellagic acid and radical scavenging capacity in various raspberry (Rubus spp.) cultivars, Food Chemistrv, 132(3), pp. 1495-1501.

18. Radočai O, Vuiasinović V. Dimić E. Basić Z. (2014), Blackberry (Rubus fruticosus L.) and raspberry (Rubus idaeus L.) seed oils extracted from dried press pomace after longterm frozen storage of berries can be used as functional food ingredients, European Journal of Lipid Science and Technology, 116(8), pp.1015-1024.

19. Đorđević R., Nikićević N., Leskošek-Čukalović I., Nikšić M., Despotović S., Veljović M., Vunduk J. (2012), The effect of fermentation conditions on polyphenol content of raspberry wine, 6th European Congress on Food, Institute of Food Technology, Novi Sad, Serbia, pp. $1087-1092$.

20. Kalušević A., Đorđević R., Lević S., Vunduk J., Leskošek-Čukalović I., Nikićević N., Nedović V. (2012), Raspberry wine fermentation by immobilized yeast cells, $20^{\text {th }}$ Internetional Conference on Bioencapsulation, Queens University, Orillia, Canada, pp. $150-151$.

21. Đorđević R., Nikićević N., Lević S., Kalušević A., Gibson B., Čadež N., Nedović V. (2014), Raspberry wine fermentation by different biocatalysts: immobilized and suspended yeast cells, EU Project Collaborations: Challenges for Research Improvements in Agriculture, University of Belgrade. Belgrade, Serbia pp. 57.

22. Barba F.J., Galanakis C.M., Esteve M.J., Frigola A., Vorobiev E. (2015), Potential use of pulsed electric technologies and ultrasounds to improve the recovery of high-added value compounds from blackberries, Journal of Food Engineering, 167, pp. 38-44. 